\title{
Game Edukasi pada Mata Pelajaran Dasar Listrik dan Elektronika Berbasis Android
}

\author{
Muhammad \\ Badruzzaman \\ Program Studi \\ Pendidikan Vokasional \\ Teknik Elektro FKIP \\ Universitas Sultan \\ Ageng Tirtayasa Serang, \\ Indonesia \\ muhammadbadruzzaman0@gmail.com
}

\author{
Didik Aribowo \\ Program Studi \\ Pendidikan Vokasional \\ Teknik Elektro FKIP \\ Universitas Sultan \\ Ageng Tirtayasa Serang, \\ Indonesia \\ d_aribowo@untirta.ac.id
}

\author{
Desmira \\ Program Studi \\ Pendidikan Vokasional \\ Teknik Elektro FKIP \\ Universitas Sultan \\ Ageng Tirtayasa Serang, \\ Indonesia \\ desmira@untirta.ac.id
}

\begin{abstract}
Motivation for studetns in learning is due to the lack of attractive interactive learning media that makes students easy to underatand the material in class so that students have difficulty understanding the material presented by the teacher. The purpose of the study is to develop educational games as media on basic subjects of electricity and electronics and proxy tests on learning media based on student responses. The subjects of this study is an $X$ class of electrical engineering at SMK public school of 4 serang cities of 21 people as responders. Research and development $(R \& D)$ and use the waterfall model as a stage for developing the software. The development model consists of 5 stages, whoch are (1) analyses and rems, (2) system design and software, (3) implementation and testing of units, (4) integration and testing of system, (5) operations and maintenance. Studies show that an average value of 48,8 from student responses. Where as the results of the material worthiness show an average value of 51,7 with a range of scores $x \geq 45$ "most appropriate", $45>x \geq 37,5$ "appropriate" and $x<30$ "not appropriate". Based on the research that has been done, it can be concluded that android based educational games are based on basic subjects of electricity and electronics can be made into interactive learning media in the classroom with the "Most Appropriate" category of student responses as well as material tests and media.
\end{abstract}

Keywords: Educational media android based, education games, basic electric and electronics.

\section{PENDAHULUAN}

Pendidikan memiliki makna yang sangat penting dalam kehidupan. Lewat pendidikan, bisa diukur maju mundurnya sebuah negara. Sebuah negara akan tumbuh pesat dan maju dalam segenap bidang kehidupan jika ditopang oleh pendidikan yang berkualitas. Sebaliknya, kondisi pendidikan yang kacau dan amburadul akan berimplikasi pada kondisi negara yang karut-marut[1].

Pendidikan di dalamnya terdapat proses pembelajaran. Komponen dalam pembelajaran termasuk guru, siswa, sarana prasarana, kurikulum, metode pembelajaran, media pembelajaran dan lain sebagainya. Kualitas pendidikan sebenarnya ditentukan oleh keterpaduan antara seluruh komponen pembelajaran[2].

Pembelajaran efektif adalah ketika guru menyampaikan materi, selanjutnya ada interaksi antara guru dan siswa, yang mana pada akhirnya siswa memahami materi pembelajaran. Penggunaan media sebenarnya lebih efektif dalam dunia pendidikan, akan tetapi kendala yang terjadi di lapangan adalah pemanfaatan atau penggunaan media pembelajaran yang masih kurang. Hal itu bisa disebabkan karena seorang guru yang belum mampu untuk mengolah atau membuatnya[3].

Berdasarkan uraian diatas, penulis tertarik membuat suatu media pembelajaran berupa Game Edukasi dengan menggunakan aplikasi Unity Game 3D. Game edukasi terbukti lebih efisien dibandingkan dengan metode pembelajaran konvensional yang bersifat pasif bagi anak, game edukasi memiliki permasalahan nyata yang dikemas dalam kreatif visual untuk memicu logika dan mempengaruhi perilaku positif anak dalam belajar[4].

Belajar dapat menumbuhkan rasa ingin tahu, pengetahuan lebih, serta dorongan untuk mengetahui sesuatu yang belum diketahui sebelumnya. Kegiatan belajar dapat dilaksanakan oleh individu itu sendiri, oleh kelompok belajar, ataupun berpasanganpasangan. Nyatanya dalam belajar seseorang harus mengetahui keadaan lingkungan yang terjadi pada saat itu dapat dikatakan harus peka dan melihat lingkungan yang mana tujuannya supaya tujuan dalam belajar yang diharapkan dapat tercapai[5].

Manfaat media pembelajaran memperjelas penyampaian pesan materi pembelajaran sehingga dapat meningkatkan perhatian dan interaksi siswa serta dapat menyamakan persepsi siswa. Disamping itu manfaat media pembelajaran dapat mempermudah guru dalam menyampaikan materi pembelajaran, namun seberapa besar pun manfaat media pembelajaran tidak akan bisa menggantikan guru sepenuhnya[6].

Urgensi penelitian ini supaya siswa mudah memahami materi pelajaran dasar listrik di kelas $\mathrm{X}$ 
SMK Negeri 4 kota serang. Kurangnya sarana alat bantu pembelajaran yang disediakan oleh sekolah menjadi salah satu pemicu rendahnya minat belajar peserta didik, terutama dalam menghadapi Program Keahlian praktikum. Materi dasar listrik dan elektronika menjadi dasar pembelajaran yang diterapkan di dunia industri, menjadi salah satu materi bahan ajar bagi siswa jurusan agar dapat berkembang memenuhi tuntutan di dunia industri.

\section{TEORI DASAR}

Game adalah suatu hiburan yang berbentuk multimedia berupa media elektronik yang dikemas semenarik mungkin agar pemainnya dapat terinspirasi untuk menghasilkan kepuasan pada batinnya[7].

Game edukasi ialah sebuah permainan khusus yang didesain sebagai bahan ajaran kepada orang kepada orang yang memainkannya, menambahkan suatu konsep.

Permainan berbasis edukasi adalah suatu alat yang didesain untuk meningkatkan pola pemikiran serta peningkatan pikiran pada suatu hal dan cara menyelsaikan suatu permasalahan[8].

Android ialah perangkat mobile yang dijadikan sebuah operasi sistem yang biasanya memiliki virtual machine dan beberapa aplikasi utama. Android adalah bagian perubahan dari kernel Linux[9].

Perusahaan bernama Android, Inc. Perusahaan ini merupakan perusahaan start-up kecil yang lokasinya di Palo Alto, California, Amerika Serikat yang didirikan oleh Andy Rubin, Rich Miner, Nick Sears dan Chris White. Pada bulan Juli 2005, perusahaan ini dipindah kepemilikan kepada Google dan orang yang mendirikan sebelumnya ikut berkumpul menjadi satu ke Google. Andy Rubin juga sampai dijadikan Wakil Presiden divisi Mobile dari Google.

\section{METODE PENELITIAN}

Metode penelitian pengembangan media pembelajaran yaitu dengan metode penelitian pengembangan atau dikenal dengan Research and Development (R \& D). Penelitian ini bertujuan mengambil kegiatan proses dasar seperti spesifikasi, pengembangan, validasi, dan evolusi dan mempresentasikannya sebagai fase-fase proses yang berbeda seperti spesifikasi persyaratan, perancangan perangakat lunak, implementasi, pengujian dan seterusnya.

Dalam penelitian pengembangan ini menggunakan model waterfall. Penelitian dan pengembangan menggunakan model waterfall, karena model ini salah satu rekayasa perangkat lunak dan lebih sesuai. Model ini dirasa sangat cocok untuk penelitian, karena proses pengembangan ini lebih spesifik ke arah software atau perangkat lunak, dimana penelitian ini bertujuan membuat sebuah game edukasi untuk proses pembelajaran.

Waterfall model terdiri dari lima tahapan yaitu : (1) Analisis dan Definisi persyaratan, (2) Perancangan sistem dan perangkat lunak, (3)
Implementasi dan pengujian unit, (4) Integrasi dan pengujian sistem dan (5) Operasi dan pemeliharaan. Berikut tahap-tahap penelitian pengembangan waterfall dapat dilihat pada Gambar 1[10].

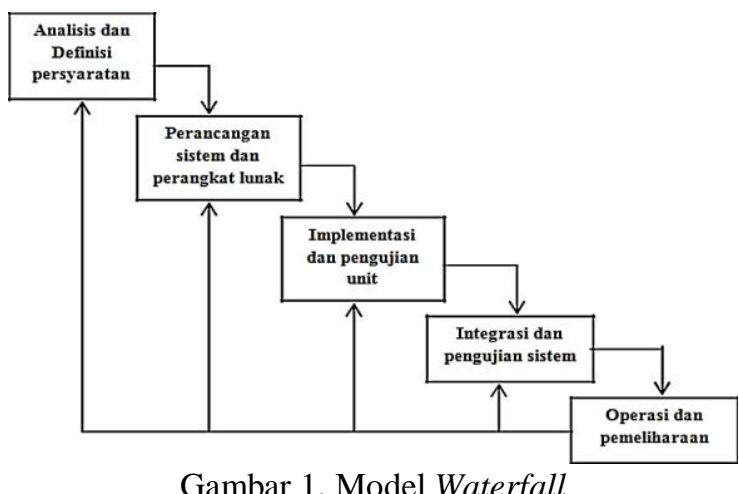

Subyek penelitian pengembangan ini adalah peserta didik kelas X di SMK Negeri 4 Kota Serang Jurusan Teknik listrik yang mengambil mata pelajaran dasar listrik dan elektronika sebanyak 21 siswa.

\section{HASIL DAN PEMBAHASAN}

Berdasarkan penelitian telah dilaksanakan yang berupa pengembangan media pembelajaran game edukasi Elektronika Listrik didapatkan hasil sebagai berikut:

A. Pengembangan Media Pembelajaran

Tahap pertama yaitu analisis dan definisi persyaratan. Tahap analisis bertujuan untuk mengetahui keadaan lapangan agar peneliti dapat menyesuaikan tujuan penelitian dengan kebutuhan sekolah. Pada tahap ini, hal yang pertama kali dilakukan oleh peneliti adalah melakukan wawancara mengenai kurikulum yang berlaku dengan guru mata pelajaran Dasar Listrik dan Elektronika kelas X di SMKN 4 Kota Serang, yaitu Ibu Siti Rohaeni. Kurikulum yang digunakan di sekolah ini yaitu Kurikulum 2013. Berikut adalah kompetensi dasar yang digunakan pada penelitian ini di Tabel 1.

Tabel 1. Kompetensi dasar mata pelajaran Dasar Listrik dan Elektronika

\begin{tabular}{|l|l|}
\hline \multicolumn{1}{|c|}{$\begin{array}{c}\text { Kompetensi } \\
\text { dasar }\end{array}$} & \multicolumn{1}{c|}{$\begin{array}{c}\text { Indikator pencapaian } \\
\text { kompetensi }\end{array}$} \\
\hline \multirow{2}{*}{$\begin{array}{l}\text { Memahami } \\
\text { hukum-hukum } \\
\text { kelistrikan dan } \\
\text { elektronika }\end{array}$} & $\begin{array}{l}\text { Memahami Hukum-hukum } \\
\text { Kelistrikan }\end{array}$ \\
\cline { 2 - 2 } & $\begin{array}{l}\text { Memahami Hukum-hukum } \\
\text { Elektronika }\end{array}$ \\
\hline $\begin{array}{l}\text { Menerapkan } \\
\text { Hukum-hukum } \\
\text { kelistrikan dan } \\
\text { elektronika }\end{array}$ & $\begin{array}{l}\text { Menerapkan Hukum-hukum } \\
\text { kelistrikan pada rangkaian } \\
\text { elektronika. }\end{array}$ \\
\cline { 2 - 2 } & $\begin{array}{l}\text { Mengaplikasikan Hukum- } \\
\text { hukum kelistrikan pada } \\
\text { rangkaian }\end{array}$ \\
\hline
\end{tabular}




\section{Game Edukasi pada Mata Pelajaran Dasar Listrik dan Elektronika Berbasis Android}

Tahap kedua yaitu perancangan sistem perangkat lunak. Pada tahap ini dijelaskan rancanganrancangan yang dibuat untuk menghasilkan media pembelajaran berupa game edukasi. Pada tahap ini terdapat rancangan berupa pembuatan desain game edukasi secara keseluruhan (storyboard). Ketika game edukasi dioperasikan, pada halaman awal terdapat judul game edukasi yaitu "Elektronika Listrik". Judul dibuat berdasarkan pemilihan materi untuk mata pelajaran yang akan diajarkan, yaitu dasar listrik dan elektronika serta di atas judul terdapat identitas universitas asal peneliti (Universitas Sultan Ageng Tirtayasa), jurusan asal peneliti (Pendidikan Vokasional Teknik Elektro), dan sekolah tempat melakukan penelitian (SMKN 4 Kota Serang). Pada menu utama game edukasi ini terdapat beberapa fitur, yaitu "mulai", "pembelajaran", "pengaturan", dan "keluar". Masing-masing tombolnya yaitu, tombol bulat yg ada di tengah-tengah keterangan "mulai", "pembelajaran", "pengaturan" dan "keluar"

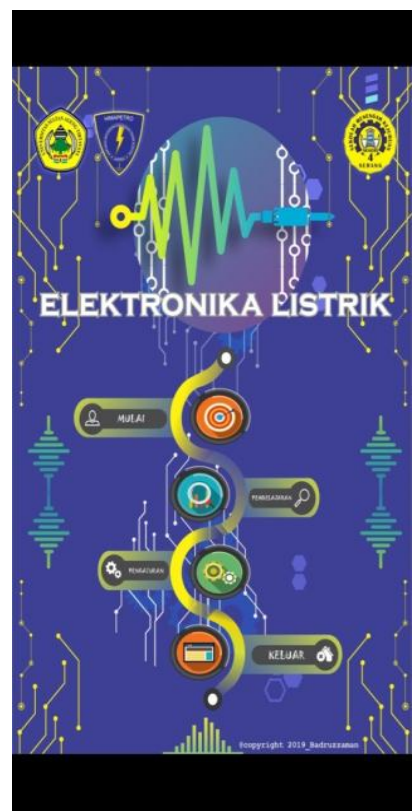

Gambar 2. Desain Tampilan Awal Game Edukasi

Pada halaman kedua adalah halaman setelah menekan tombol "mulai" terdapat tiga menu yang dapat dimainkan oleh siswa untuk menyelesaikan game edukasi, yaitu tebak gambar, rangkaian, soalsoal latihan dan dibawah dari ketiga fitur tersebut terdapat tombol kembali berwarna jingga untuk mengarahkan ke halaman awal.

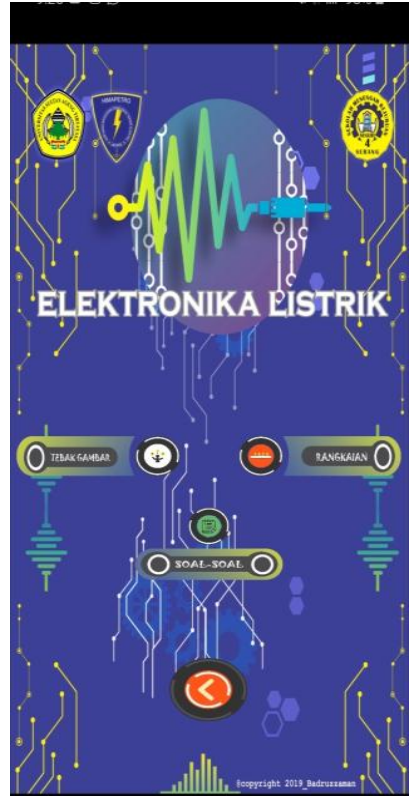

Gambar 3. Halaman Kedua Game Edukasi

Pada game edukasi tebak gambar, terdapat 10 gambar yang harus ditebak oleh siswa untuk menyelesaikan game edukasi ini. Tampilan halaman game dapat dilihat pada Gambar 4. Pada halaman game edukasi "rangkaian", sebelum memulai game terdapat cara bermain yang harus dipahami oleh siswa terlebih dahulu. Dapat dilihat pada Gambar 5. Pada halaman game edukasi "soal-soal" latihan, sebelum memulai game terdapat cara bermain yang harus dipahami terlebih dahulu oleh siswa agar dapat memulai game, dapat dilihat pada Gambar 4.

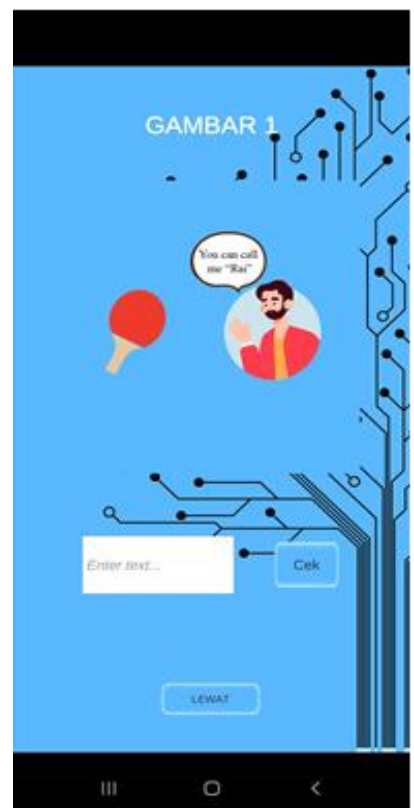

Gambar 4. Tampilan Game Edukasi Tebak Gambar 

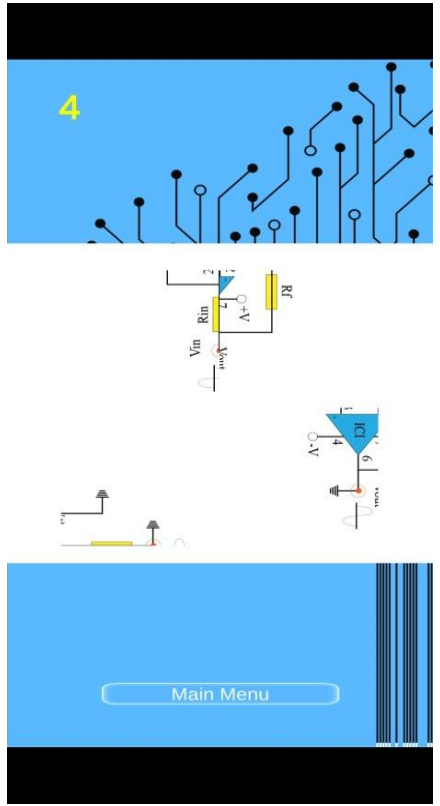

Gambar 5. Tampilan Game Edukasi Rangkaian

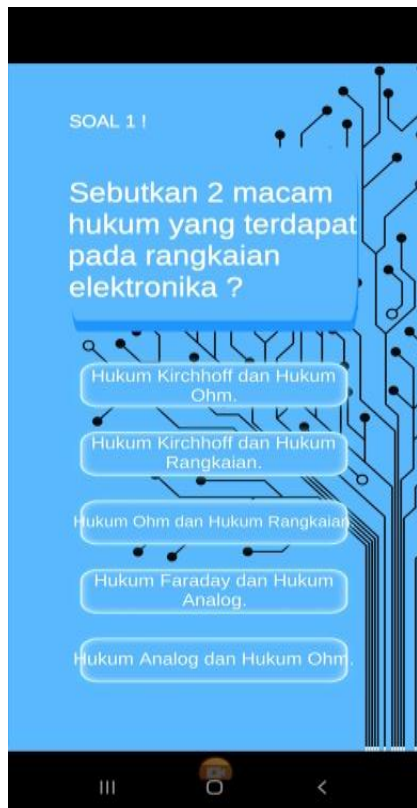

Gambar 6. Tampilan Game Edukasi Soal-soal Latihan

Tahap ketiga yaitu Implementasi, pada tahap ini menjelaskan pada setiap halaman game edukasi, yang terdiri dari tebak gambar, rangkaian dan soal-soal. Pada halaman awal tebak gambar, sebelum siswa memainkan game edukasi ini, siswa akan disajikan fitur tata cara bermain seperti pada Gambar 7 .

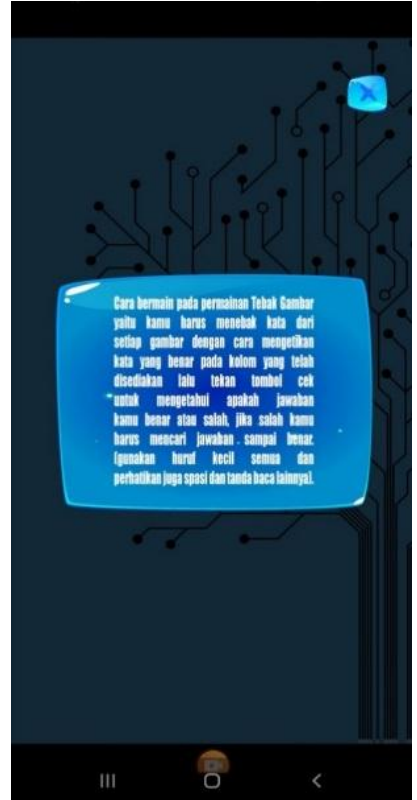

Gambar 7. Cara Bermain tebak gambar

Setelah selesain membaca, agar bisa melanjutkan ke permainan tebak gambar, terlebih dahulu menekan tombol "x" yang ada di ujung kanan atas pada tampilan cara bermain tebak gambar.

Pada soal tebak gambar ini terdapat 10 soal yang beragam. Siswa diharuskan menjawab pada kolom enter text dan jika sudah yakin dengan jawabannya, maka siswa dapat menekan tombol "cek" agar terdeteksi jawaban yang dimasukkan benar atau salah. Berikut 10 petunjuk gambar pada tebak gambar terdapat pada Gambar 8.

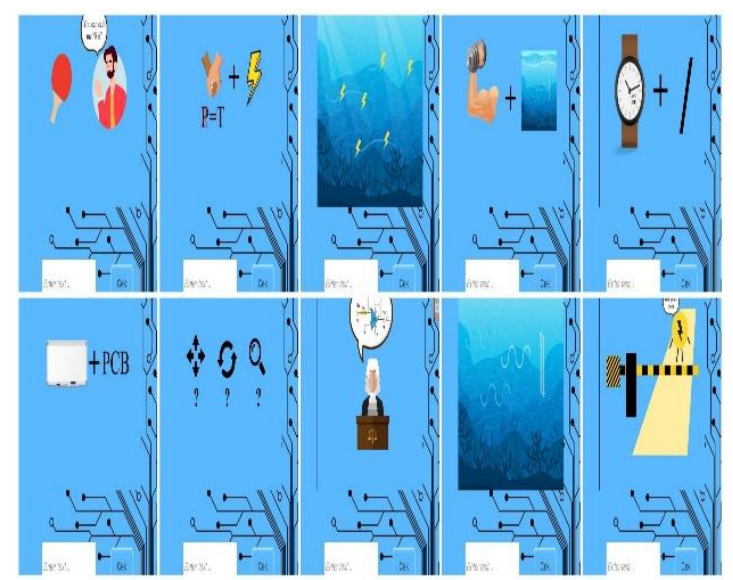

Gambar 8. 10 Soal "Tebak Gambar"

Selanjutnya halaman pada rangkaian. Pada halaman awal rangkaian, siswa juga disajikan fitur tata cara bermain sebelum memainkan game dan dapat melanjutkan permainan jika sudah menekan tombol " $\mathrm{x}$ " diujung kanan atas. Pada halaman game edukasi rangkaian, terdapat beberapa potongan rangkaian listrik dan elektronika yang harus disusun oleh siswa agar menjadi suatu gambar rangkaian listrik dan elektronika yang utuh dengan waktu yang terbatas. Berikut 10 soal yang terdapat pada Gambar 9. 


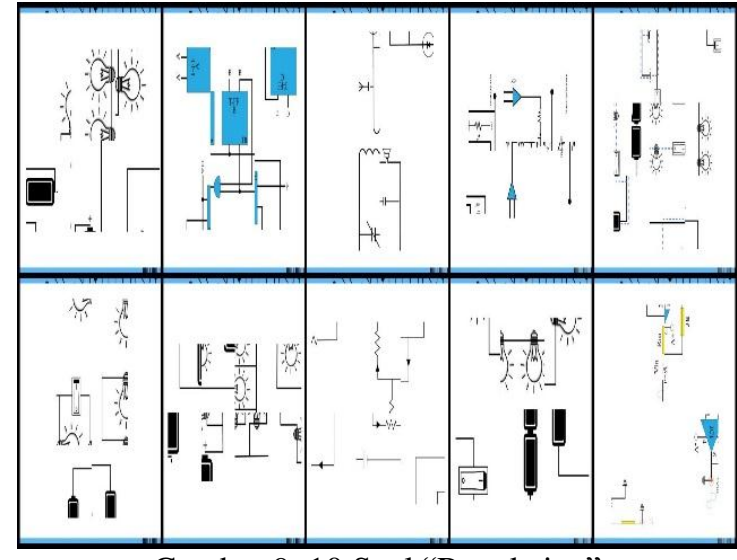

Gambar 9. 10 Soal "Rangkaian"

Pada halaman awal soal-soal pun terdapat fitur tata cara bermain sebelum memulai game edukasi dan dapat menekan tombol " $x$ " jika sudah selsai membaca tata cara bermain. Terdapat 10 soal pilihan ganda mengenai dasar listrik dan elektronika yang harus dijawab oleh siswa. Berikut 10 soal pilihan ganda pada game edukasi jenis "soal-soal" pada Gambar 10.

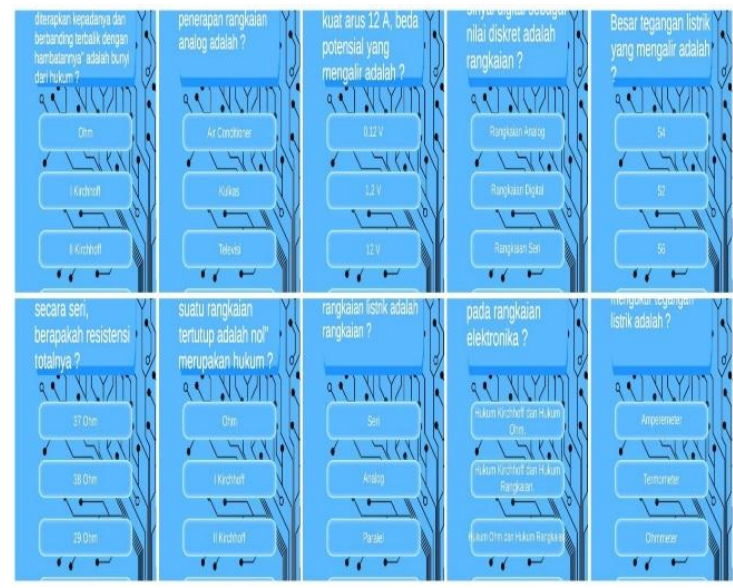

Gambar 10. 10 Soal "Soal-soal"

Tahap keempat yaitu pengujian, tahap ini merupakan tahap dimana siswa mengenal fitur-fitur yang ada di menu dan siswa memainkan game edukasi ini.

Pada fitur tebak gambar siswa harus mengisi jawaban berdasarkan petunjuk yang dikasih lewat gambar, jawabannya selalu berhubungan dengan mata pelajaran dasar listrik dan elektronika. Apabila siswa sudah menyelesaikan game pada tebak gambar, akan ditampilkan halaman skor di akhir. Halaman skor tebak gambar bisa dilihat pada Gambar 11 .

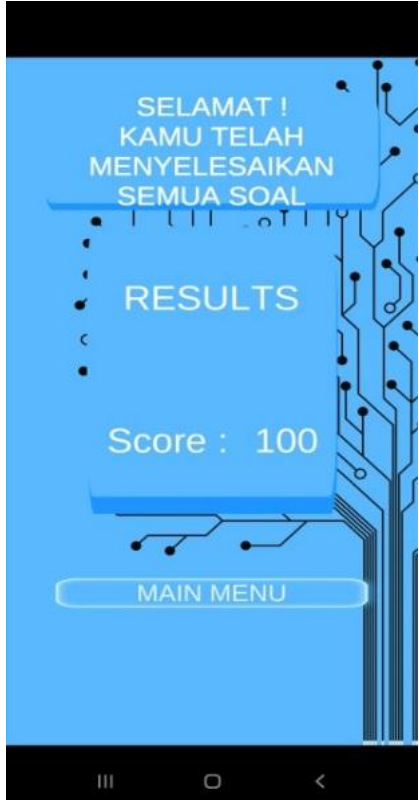

Gambar 11. Halaman skor pada "tebak gambar"

Pada fitur rangkaian siswa harus menyelsaikan potongan gambar yang ada, untuk dijadikan suatu rangkaian listrik dan elektronika. Pada setiap soal terdapat waktu untuk mengerjakannya. Apabila sudah selesai siswa akan ditampilkan halaman dengan tulisan "SELAMAT ! KAMU TELAH BERHASIL MENYUSUN SEMUA GAMBAR DENGAN BENAR" dan terdapat tombol "main menu" untuk kembali ke halaman awal menu. Di game edukasi rangkaian ini tidak terdapat halaman skor, karena pada game edukasi ini, siswa dihibur untuk bermain game.

Pada fitur soal-soal, siswa harus menjawab pertanyaan dan memilih salah satu jawaban yang tersedia. Apabila siswa sudah menyelesaikan game edukasi ini, akan ditampilkan halaman 'skor' yang diperoleh siswa. Terdapat pada Gambar 12.

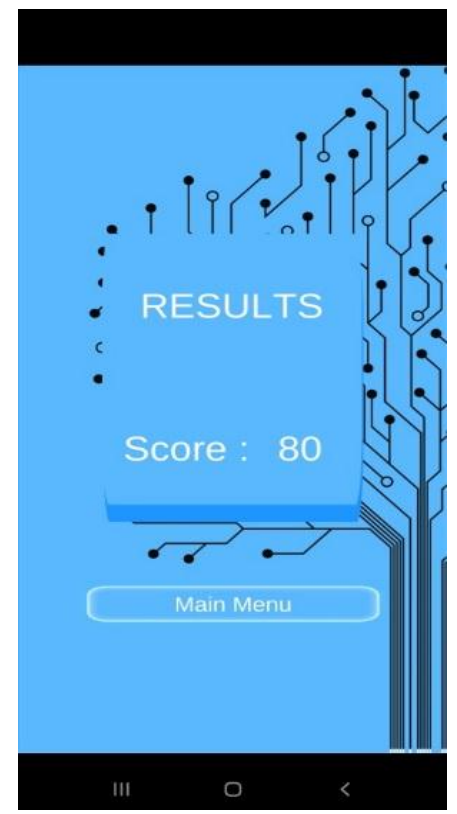

Gambar 12. Halaman skor pada "soal-soal" 
B. Kelayakan Media Pembelajaran Ditinjau dari Ahli Media dan Ahli Materi

Tingkat kelayakan media pembelajaran ini dapat dilihat dari hasil ahli materi dan ahli media. Validasi ini ditujukan agar mengetahui apakah game edukasi yang dibuat oleh peneliti sudah sesuai kriteria yang diaplikasikan di sekolah. Berikut hasilnya:

Penilaian Ahli Media

Pengujian ahli media ini berasal dari 1 dosen dan 2 guru listrik smkn 4 kota serang. Skor penilaian ahli media dapat dilihat pada Tabel 2 .

Tabel 2. Hasil validasi ahli media

\begin{tabular}{|c|c|c|c|c|c|c|}
\hline \multirow[b]{2}{*}{$\begin{array}{l}\mathrm{N} \\
\mathrm{O}\end{array}$} & \multirow[b]{2}{*}{$\begin{array}{c}\text { Aspek } \\
\text { Kriteria }\end{array}$} & \multirow{2}{*}{$\begin{array}{l}\text { No. } \\
\text { But } \\
\text { ir }\end{array}$} & \multirow{2}{*}{$\begin{array}{l}\text { Nil } \\
\text { ai } \\
\text { Ma } \\
\text { X }\end{array}$} & \multicolumn{3}{|c|}{ Validator } \\
\hline & & & & $\begin{array}{l}\text { Peng } \\
\text { uji } 1\end{array}$ & $\begin{array}{l}\text { Peng } \\
\text { uji } 2\end{array}$ & $\begin{array}{l}\text { Peng } \\
\text { uji } 3\end{array}$ \\
\hline \multirow{5}{*}{1.} & \multirow{5}{*}{$\begin{array}{c}\text { Desain } \\
\text { Presenta } \\
\text { si }\end{array}$} & 1 & 4 & 4 & 3 & 3 \\
\hline & & 2 & 4 & 4 & 4 & 4 \\
\hline & & 3 & 4 & 3 & 4 & 3 \\
\hline & & 4 & 4 & 4 & 4 & 4 \\
\hline & & 5 & 4 & 3 & 3 & 4 \\
\hline \multirow{5}{*}{2.} & \multirow{5}{*}{$\begin{array}{c}\text { Penggun } \\
\text { aan }\end{array}$} & 6 & 4 & 3 & 4 & 3 \\
\hline & & 7 & 4 & 3 & 4 & 3 \\
\hline & & 8 & 4 & 3 & 3 & 4 \\
\hline & & 9 & 4 & 3 & 4 & 3 \\
\hline & & 10 & 4 & 3 & 4 & 4 \\
\hline \multirow{5}{*}{3.} & \multirow{5}{*}{$\begin{array}{c}\text { Aksebili } \\
\text { tas }\end{array}$} & 11 & 4 & 3 & 3 & 4 \\
\hline & & 12 & 4 & 3 & 3 & 3 \\
\hline & & 13 & 4 & 4 & 3 & 3 \\
\hline & & 14 & 4 & 3 & 4 & 3 \\
\hline & & 15 & 4 & 4 & 4 & 4 \\
\hline \multicolumn{4}{|c|}{ Total } & 50 & 54 & 52 \\
\hline
\end{tabular}

Berdasarkan data yang diperoleh pada Tabel 2, hasil validasi media dari tiga penguji memperoleh nilai rata-rata sebesar 52, sehingga dapat dilihat bahwa media game edukasi yang sudah diteliti masuk dalam kategori "Sangat Layak". Dari hasil yang didapat disimpulkan bahwa media game edukasi Elektronika Listrik layak untuk digunakan sebagai media pembelajaran.

\section{Penilaian Ahli Materi}

Penilaian media pembelajaran game edukasi Elektronika Listrik oleh ahli materi berasal dari 1 dosen dan 2 guru listrik smkn 4 kota serang. Validasi ini ditujukan agar mengetahui apakah materi game edukasi sudah sesuai kriteria. Skor penilaian ahli materi dapat dilihat pada Tabel 3.

Tabel 3. Hasil validasi ahli media

\begin{tabular}{|c|c|c|c|c|c|c|}
\hline \multirow[b]{2}{*}{$\begin{array}{l}\mathrm{N} \\
\mathrm{O}\end{array}$} & \multirow[b]{2}{*}{$\begin{array}{c}\text { Aspek } \\
\text { Kriteria }\end{array}$} & \multirow{2}{*}{$\begin{array}{l}\text { No. } \\
\text { But } \\
\text { ir }\end{array}$} & \multirow{2}{*}{$\begin{array}{c}\text { Nil } \\
\text { ai } \\
\text { Ma } \\
\mathrm{X}\end{array}$} & \multicolumn{3}{|c|}{ Validator } \\
\hline & & & & $\begin{array}{l}\text { Peng } \\
\text { uji } 1\end{array}$ & $\begin{array}{l}\text { Peg } \\
\text { uji } 2\end{array}$ & $\begin{array}{l}\text { Peng } \\
\text { uji } 3\end{array}$ \\
\hline \multirow{4}{*}{1.} & \multirow{4}{*}{$\begin{array}{c}\text { Kualitas } \\
\text { Isi dan } \\
\text { Tujuan }\end{array}$} & 1 & 4 & 4 & 3 & 4 \\
\hline & & 2 & 4 & 3 & 4 & 3 \\
\hline & & 3 & 4 & 3 & 4 & 3 \\
\hline & & 4 & 4 & 3 & 3 & 4 \\
\hline
\end{tabular}

\begin{tabular}{|c|c|c|c|c|c|c|}
\hline & & 5 & 4 & 3 & 3 & 4 \\
\hline & & 6 & 4 & 3 & 4 & 4 \\
\hline & & 7 & 4 & 3 & 4 & 3 \\
\hline & & 8 & 4 & 3 & 3 & 4 \\
\hline \multirow{8}{*}{2.} & \multirow{7}{*}{$\begin{array}{c}\text { Kualitas } \\
\text { Intruksi } \\
\text { onal }\end{array}$} & 9 & 4 & 3 & 4 & 3 \\
\hline & & 10 & 4 & 3 & 4 & 3 \\
\hline & & 11 & 4 & 3 & 4 & 3 \\
\hline & & 12 & 4 & 3 & 3 & 4 \\
\hline & & 13 & 4 & 4 & 3 & 3 \\
\hline & & 14 & 4 & 4 & 4 & 4 \\
\hline & & 15 & 4 & 3 & 4 & 4 \\
\hline & \multicolumn{3}{|c|}{ Total } & 48 & 54 & 53 \\
\hline
\end{tabular}

Berdasarkan data yang diperoleh pada tabel 3, hasil validasi materi dari tiga penguji mendapatkan rata-rata sebesar 51,7, sehingga menunjukan bahwa materi game edukasi yang sudah diteliti masuk dalam kategori "Sangat Layak". Dari hasil ini dapat disimpulkan bahwa materi game edukasi Elektronika Listrik layak untuk digunakan sebagai materi yang dapat dimuat pada game edukasi.

Respon Siswa atau Pengguna

Setelah melakukan validasi dari ahli media dan materi serta mendapatkan kategori "Sangat Layak", peneliti melaksanakan validasi pada pengguna. Subjek penelitian yaitu siswa kelas X di SMK N 4 Kota Serang yang berjumlah 21 orang. Hasil validasi pengguna memperoleh nilai rata-rata 48,4, sehingga menunjukkan bahwa game edukasi ini berdasarkan respon pengguna termasuk ke dalam kategori "Sangat Layak". Berikut rangkuman tabelnya terdapat pada Tabel 4.

Tabel 4. Hasil uji validasi pengguna

\begin{tabular}{c|c}
\hline Rata-rata Skor & Kategori \\
\hline 48,4 & Sangat Layak \\
\hline
\end{tabular}

Maka dapat disimpulkan game edukasi Elektronika listrik dilihat dari seluruh aspek, dikategorikan sangat layak untuk digunakan sebagai media pembelajaran.

\section{KESIMPULAN}

Berdasarkan hasil penelitian Pengembangan media pembelajaran game edukasi berbasis Android ini dapat dijalankan dengan sangat baik. Metode penelitian yang digunakan yaitu Research and Development dengan model pengembangan waterfall. Software pembuatan game edukasi ini dengan aplikasi Unity Game 3D dan aplikasi pendukung dengan Corel Draw, Adobe Illustrator, serta aplikasi Microsoft Visual Studio.

Berdasarkan hasil uji kelayakan game edukasi Elektronika Listrik, respon siswa menunjukkan nilai rata-rata 48,4 maka, kesimpulan yang diambil bahwa game edukasi Elektronika Listrik "Sangat Layak" dan menunjukkan hasil yang positif terhadap respon siswa.

Berdasarkan hasil uji kelayakan media dan materi pada game edukasi Elektronika Listrik menunjukkan nilai rata-rata sebesar 52 dan 51,7 maka, 
dapat disimpulkan bahwa media dan materi game edukasi Elektronika Listrik "Sangat Layak" untuk digunakan sebagai media pembelajaran.

\section{DAFTAR PUSTAKA}

[1] W. Sanjaya, Strategi Pembelajaran Berorientasi Standar Proses Pendidikan. Jakarta: Kencana Prenada Media, 2011.

[2] S. Sagala, Konsep dan Makna Pembelajaran Untuk Membantu Menyelesaikan Problematika Belajar dan Mengajar. Bandung: Alfabeta, 2013.

[3] W. Sanjaya, Media Komunikasi Pembelajaran. Jakarta: Prenadamedia Group, 2016.

[4] J. Banyte and A. Gadeikiene, "The Effect of Consumer Motivation to Play Games on Video Game-playing Engagement," Procedia Econ. Financ., vol. 26, no. 15, pp. 505-514, 2015, doi: 10.1016/s2212-5671(15)00880-1.

[5] H. Wibawanto, Dasar Elektronika. Jakarta: Erlangga, 2016.

[6] M. Yamin, Teori dan Metode Pembelajaran. Malang: Madani, 2015.

[7] I. Binanto, Multimedia Digital-Dasar Teori dan Pengembangannya. Yogyakarta: Andi, 2010.

[8] Handriyantini, Permainan Edukatif Berbasis Komputer Untuk Siswa Sekolah Dasar. Malang: Sekolah Tinggi, 2009.

[9] Andry, Android A sampai Z. Jakarta: PCplus, 2011.

[10] I. Sommerville, Software Engineering (Rekayasa Perangkat Lunak). Jakarta: Erlangga, 2003. 